\title{
Harmonization of LCA methodologies for the metal and mining industry
}

\author{
Nicholas Santero $^{1} \cdot$ Josh Hendry $^{1}$ (D) \\ Received: 30 June 2015 / Accepted: 22 December 2015 / Published online: 22 January 2016 \\ (C) The Author(s) 2016. This article is published with open access at Springerlink.com
}

\begin{abstract}
Purpose The metal and mining industry routinely conducts life cycle assessment studies to monitor and document the potential environmental impacts of their products. These studies are typically conducted independently by the various commodity associations. To facilitate alignment of these methodologies, a working group comprised of interested industry organizations and their representatives was formed to propose uniform recommendations for key methodological choices.

Methods Existing methodologies used by the participating associations were reviewed to identify areas of alignment as well as areas which could benefit from discussions and alignment. Recommendations for selected topics were then developed through a series of moderated discussions among the participating organizations throughout 2012 and 2013. Efforts were taken in the creation of the document to ensure alignment with the international standards ISO 14040 (2006) and ISO 14044 (2006). Four methodology issues were chosen to be addressed with respect to industry alignment: system boundary, recycling allocation, co-product allocation, and impact assessment categories.

Results and discussion Recommendations for system boundary conclude that boundaries should include end-of-life disposal and recycling and, whenever possible, the product use phase, particularly for material and product comparison. For co-product allocation methods, the recommendations were based on the type of co-products being produced and included a range of options to guide practitioners' decisions. It was
\end{abstract}

Responsible editor: Andrea J. Russell-Vaccari

Josh Hendry

josh.hendry@thinkstep.com

thinkstep, 170 Milk Street, 3rd Floor, Boston, MA 02109, USA recommended for recycling allocation that practitioners use the avoided burden methodology. Lastly, for the life cycle impact assessment stage, it was recommended that life cycle assessments (LCAs) on metal and mining products should report the following impact categories: global warming potential, acidification potential, eutrophication potential, photochemical oxidant creation potential, and ozone depletion potential. It was recommended that inclusion of other impact categories will be periodically re-evaluated by the metal industry. Further, the recommendation is that, while impact categories included are limited to the five above, all life cycle inventory (LCI) datasets themselves should contain accurate and comprehensive inventory data, given reasonable accessibility and data collection cost constraints.

Conclusions Methodological alignment for LCA studies in the metal and mining industry will lead to improved consistency and applicability of the LCA data and results. Specifically, these recommendations improve the consistency of decisions regarding system boundary, recycling allocation, co-product allocation, and impact assessment categories. Further research is suggested to improve the specificity of certain recommendations (e.g., allocation), as well as expand the scope of the harmonization efforts to include other methodological decisions.

Keywords Co-product allocation · Harmonization · Impact assessment $\cdot$ Industry alignment $\cdot$ LCA $\cdot$ Metals $\cdot$ Life cycle methodologies $\cdot$ Mining $\cdot$ Recycling allocation $\cdot$ System boundary

\section{Introduction}

Metals constitute a major category of raw materials extracted from the environment. Metals can be found in a vast range of 
product and economic sectors, ranging from buildings and infrastructure to electronics and the food and pharmaceutical sectors. To foster the sustainable development of metalcontaining products, the metal industry has embraced the use of life cycle assessment (LCA) as described by the international standards ISO 14040 (2006) and ISO 14044 (2006) to evaluate and communicate the environmental impacts of its products.

The completion and continued production of LCA studies by the individual metal and mineral associations has fostered the need to develop a harmonized approach to life cycle inventory and assessment methodologies within the industry. This article offers guidance to align methodologies where appropriate, recognizing that complete alignment of all aspects of the methodologies is not feasible due to the broad range of metal- or mineral-specific issues which may require approaches unique to the given material and/or its downstream uses. It should also be noted that examples of the current methodological approaches used by the various metal and mineral associations are discussed in detail in other articles in this special issue as well as through other information provided by the respective associations via published articles and association websites. A more complete discussion of the harmonization effort preceded this article and was made available by the participating associations on their respective websites in a guidance document and associated frequently asked questions document (PE International 2014).

\section{Methods}

The alignment described in this article has been created through the cooperation of numerous commodity associations ${ }^{1}$ with the intention that the guidance offered can be used by other metal and mineral commodity associations as well as life cycle practitioners within the industry. The general objectives are to address the following concerns identified by the participating organizations:

- Strengthen the ability to have a common voice on life cycle methodologies when engaging with regulators, life cycle database providers, and other external stakeholders and

- Agree on life cycle methodologies so that the industry can better align its practices.

\footnotetext{
${ }^{1}$ Participating associations include the following: Aluminum Association, Cobalt Development Institute, Eurometaux, Euromines, International Aluminium Institute, International Copper Association, International Council on Mining and Metals, International Lead Association, International Manganese Institute, International Molybdenum Association, International Stainless Steel Forum, International Zinc Association, Nickel Institute, and the World Steel Association.
}

This harmonization effort began with a comparison of existing methodologies used by participating associations and discussions regarding industry-wide challenges and opportunities for collaboration and alignment of activities across the industry. The creation of a matrix of existing methodologies used by associations highlighted several areas of alignment in existing methodologies as well as areas which were either less aligned or could benefit from discussions and alignment across the associations. The topic areas identified for further discussion included the following: system boundary, treatment of co-products, recycling allocation, and life cycle impact assessment (LCIA). Through a series of face-to-face meetings and teleconferences in 2012 and 2013, the participating organizations shared experiences and insights on each of these topics resulting in the guidance provided in this document.

\section{Results}

Section 3.1 through Section 3.4 provide a summary of each topic area identified for further discussion and the rationale for the recommendations developed by the participating associations.

\subsection{System boundary}

The selection of life cycle stages for LCAs involving metals is of key importance. Although a metal may be associated with relatively high potential impacts during its production, the use phase and the recycling of the metal at end of life can help offset production impacts relative to competing non-metal products. Essentially, a cradle-to-gate study does not capture many of the benefits from using metals and is usually a poor system boundary choice for an LCA involving metals. A cradle-to-grave study uses a more comprehensive system boundary and provides a more accurate reflection of the actual environmental impacts. In fact, per ISO definition, an LCA is always cradle-to-grave: "LCA addresses the environmental aspects and potential environmental impacts...throughout a product's life cycle from raw material acquisition through production, use, end-of-life treatment, recycling and final disposal (i.e., cradle-to-grave)" (ISO 140402006 and ISO 14044 2006). Although omission of life cycle stages is tolerated in certain applications (e.g., type III environmental product declarations following EN 15804:2012), it should be applied with caution and "only permitted if it does not significantly change the overall conclusions of the study" (ISO 14044 2006).

Nonetheless, a cradle-to-gate system boundary does have its place. Many of the metal associations involved with this research have produced cradle-to-gate studies of their metals in order to provide the LCA community the necessary data for external, cradle-to-grave studies performed by other 
practitioners. Moreover, in some cases, it is understood that the use phase is uncertain; for instance, a metal fabricator may produce an intermediate product, such as a metal sheet, but not have influence on the exact application of that sheet in a larger product. In these circumstances, cradle-to-gate studies still provide important details about the potential environmental impacts but should be used with caution and should not be compared unless functional equivalency has been established on the level of the finished product.

It may be advantageous to describe the system with more detail than the aggregated cradle-to-grave results. One example of a more granular approach is described in EN 15804 (CEN 2013). This European standard is specifically designed to harmonize the creation of type III environmental product declarations (EPDs) in the building and construction sector, although the same principles can be applied to other LCA applications and economic sectors. EN 15804 breaks the product life cycle into a predefined set of information modules: A1-3 (product stage), A4-5 (construction process stage), B1-7 (use stage), C1-4 (end-of-life stage), and D (benefits and loads beyond the system boundary). Figure 1 presents the life cycle modules defined by EN 15804. The modular breakdown of the life cycle (e.g., A1, B3) is part of the harmonized approach for EPD creation of building and construction products.

EPDs that comply with EN 15804 still may not include all modules, depending on the requirements set forth in the relevant product category rules (PCR). In addition to cradle-togate and cradle-to-grave, EN 15804 suggests using a system boundary called cradle-to-gate with options; the options typically include impacts from end-of-life processes (e.g., landfilling) and potential credits received from recycling. Although this omits the use phase of the product, it accounts for end-of-life recycling, which is an important component of the metal life cycle.

The system boundary establishes the inclusion and exclusion of certain unit processes from the life cycle. In general, LCAs should include as much information as available in order to meet the goal of the study. For non-comparative studies, the goal is often to develop the most complete representation of the product life cycle. In practice, however, it is often necessary to exclude information, usually based on lack of data or budget. Good practice stipulates - and ISO 14044 (2006) mandates - that any exclusion should be disclosed in the LCA report so that the audience knows which processes are excluded as well as the governing rationale for excluding those processes.

Comparative studies should include all phases of the life cycle. In cases where certain phases are both (1) difficult to characterize and/or calculate and (2) identical between the alternative products, these phases can be omitted and the justification explained in the documentation. However, because the excluded burdens affect the relative results (e.g., percentage differences between alternatives), all results must be reported as absolute differences.

Cutoff rules guide and set thresholds for omission due to lack of relevance on the overall results. ISO 14044 (2006)

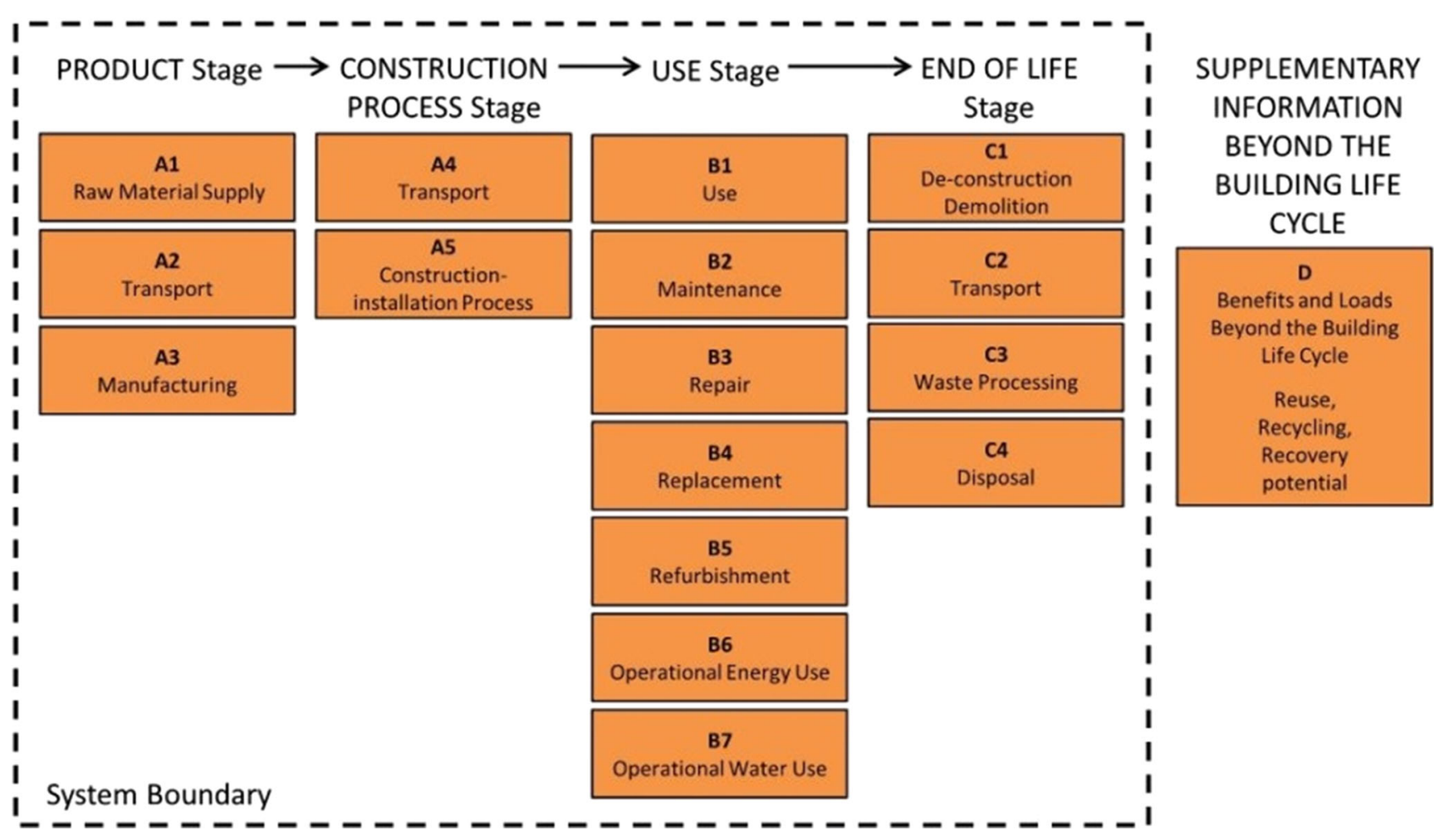

Fig. 1 Life cycle stages per EN 15804 
helps to define this rationale but does not provide guidance on actual thresholds. In addition, percentage thresholds like $x \%$ of environmental impact often suffer from the inability to establish $100 \%$ reference as one would only know it for certain after having assessed the processes which are to be excluded, at which point their exclusion would become moot. Percentage thresholds require a level of knowledge that is not matched by the underlying data and must therefore be assumed to be met by the practitioner. Cutoff rules appear to be a relic of the past when life cycle inventories for up- and downstream processes were much less available. In today's practice, data gaps can often be addressed using proxy data, thus negating the need to set and use cutoff thresholds; this approach is recommended in favor of using cutoff thresholds. It should be noted that the Product Environmental Footprint effort underway in Europe does not allow the use of cutoff criteria (European Commission 2014).

\subsubsection{Comparative assertions and the functional unit}

Life cycle assessment is routinely used as a method to compare the potential environmental impacts of two or more alternative products or services. When done correctly, these studies support comparative assertions which are defined in ISO 14044 (2006) as "environmental claim[s] regarding the superiority or equivalence of one product versus a competing product that performs the same function" (ISO 14044 2006). While comparative assertions are an important application of LCA, care must be taken in order to ensure that comparisons are fairly scoped and use comparable boundaries.

The following are two important considerations when developing comparative assertions:

- Functionally equivalent systems and

- Characterization of impacts from all relevant life cycle stages.

The second consideration when developing comparative assertions, characterization of impacts from all relevant life cycle stages, is discussed in Section 3.4. The first consideration - functionally equivalent systems - is of equal (and related) importance to ensure comparability but is often difficult to define for a metal product. ISO defines the functional unit as the "quantified performance of a product system for use as a reference unit" (ISO 14044 2006); Cooper (2003) expands on this definition, calling for the functional unit to include the magnitude of service, the duration of service, and the expected level of quality.

Metals and their alloys are typically used as input materials in downstream products, with their mass, alloy composition, geometry, and other specifications dependent upon their required function within a specific product. Ultimately, the amount of required material is based on that material's ability to perform a given function. For instance, a kilogram of metal may be able to provide the same function (e.g., structural support) as ten kilograms of plastic or wood. Similarly, one metal might perform at a higher per-mass rate than another metal; the only way to compare the two metals (or a metal and another material) is by scaling their inventories to identical functional units. The required mass of each material to provide that functional unit is then referred to as the reference flow in LCA, defined as the "measure of the outputs from processes in a given product system required to fulfill the function expressed by the functional unit" (ISO 14044 2006).

Unless the function provided by a product is properly represented by its mass (e.g., balancing weight in car wheels, counter weights in elevators or cranes), it is an inappropriate unit of comparison (Koffler et al. 2014). In many applications, mass does not capture the relevant performance characteristics of that metal within the applied product or system. In EPDs following EN 15804, mass may be used as a declared unit if "the precise function of the product or scenarios [...] is not stated or is unknown" (CEN 2013). However, declared units are not directly comparable to one another due to the lack of information regarding the function, and the proper scaling has to be performed by the user of the EPD information. Whenever metals are compared to one another or to other materials, it is imperative that identical functional units are used.

Similar to the in-depth deliberation of the functional unit, the system boundary needs to be consistently and comprehensively considered for all alternatives. The embodied impact of metal-containing materials only considers a cradle-to-gate system boundary, thus ignoring the potential advantages (and disadvantages) of using one material over another. Impacts that occur outside of those boundaries (i.e., in a cradle-to-grave perspective) are also relevant for comparative assertions. In particular, the use and end-of-life stages for compared alternatives can vary widely. Impacts on energy performance and material recyclability, for instance, can be significant or dominant contributors to the overall life cycle impact. Omitting one or more of these stages can lead to unfair comparisons that do not accurately capture the life cycle impacts of the product.

\subsection{Treatment of co-products}

Life cycle inventory (LCI) assessment relies on the ability to properly identify the environmental burdens of the product system under study. Many industrial processes yield multiple products particularly if the generation of valuable scraps and other production residues is considered. The product outputs from these systems are called co-products, defined as "any of two or more products coming from the same unit process or product system" (ISO 14044 2006). Co-products are distinguished from waste by their economic value: products and co- 
products are sellable, whereas waste has no economic value in LCA. In multi-output systems, the material and energy flows associated with these multi-output processes need to be assigned to the different co-products according to clearly stated procedures.

The following subsections discuss the treatment of multioutput processes for metal products. Recommendations are then made as to preferred treatment of co-products in metal and metal product LCAs.

\subsubsection{Methods to deal with co-products for metals}

System expansion System expansion considers alternative production routes for the co-products in a system. In practice, system expansion eliminates the co-products from the product system under study by subtracting the inventory of a functionally equivalent product produced by an alternative, monooutput process. Because system expansion avoids the need for allocation, it is generally considered a preferred method of dealing with co-products in a system. However, for some co-products, no mono-output production routes are available, which makes it infeasible to apply this method as you cannot avoid allocation by using a process inventory that is based on allocation itself. Many metals are always produced in shared processes, so it is impossible to identify an alternative production route that is both independent of other metals and representative of industry production practices. In these cases, allocation must be used to distribute the impacts of the shared process.

Metals are divided into two broad categories: base and precious. Definitions for these categories are not universal, are only loosely defined, and consider the economic value of the metal. In general, base metals have a relatively low economic value, whereas precious metals have a relatively high economic value, such as with gold and platinum. This distinction is echoed on websites that track metal prices, such as Reuters and InfoMine. Even with uncertain definitions, the concept of high and low values provides useful guidance when choosing an allocation approach (Ardente and Cellura 2012).

Mass and mass of metal allocation Allocation by mass is generally preferred when the economic value per unit of output between co-products is similar. This is due to the fact that mass remains relatively constant over time, while market value is subject to market fluctuations. As guidance, EN 15804 defines "small" as less than a $25 \%$ difference in value (CEN 2013).

For metals, it is often appropriate to allocate on the basis of the mass of the metal content in the co-products (rather than the mass of the product as a whole) as the physical relationship between co-products. This allows the allocation to focus on the valuable products (the metals) and ignore the waste products (e.g., tailings).

Economic allocation Revenue generation is the driving force behind industrial operations. Allocating based on the economic purpose of performing a given activity is known as economic (or market value) allocation. Using this approach, total impacts are allocated with respect to the economic value of the individual outputs. The market values of the outputs are averaged over a certain time period; longer periods are recommended in order to reduce the impact of random price spikes and drops. This harmonization document recommends that a 10 -year average is used; other time spans can be used so long as the price data represents economically current information that minimizes the effect of volatility. In metal systems where precious and base metals are mined as the same ore deposit, economic allocation is often the preferred allocation method. In these situations, mass allocation fails to adequately capture the main purpose of processing the ore and its downstream operations. Conversely, economic allocation captures the driver of this process (economic revenue) and uses that information to distribute the impacts.

Other allocation methods It is important to note that there are other allocation methods than have been discussed above. Two of note for the metal industry are energy-based allocation (using characteristics such as enthalpy) and relative elemental abundance in the earth's crust as noted for example by Tuusjarvi et al. (2012). These and other allocation methods could be considered as they become more developed and accepted within the scientific and metal communities.

\subsubsection{General recommendations for co-product treatment}

The treatment of co-products within an LCA, either by allocation or system expansion, is salient for metals due to the frequent occurrence of shared processes with multiple valuable products being produced. As illustrated in Fig. 2, many metals are mined together and separated during the production process. Metal industries use various procedures to assign the environmental burdens of the various metal (and non-metal) co-products that are produced.

Given the differences between product systems within the metal industry, it is challenging to provide definitive rules that prescribe the allocation methods to be used under all circumstances. Many mines, smelters, refineries, and other processes within the metal manufacturing value chain offer distinct coproduct challenges that must be reviewed on a case-by-case basis. However, best practices can still be established that move towards harmonization and provide a structured approach to deciding which methods should be prioritized in certain conditions. 


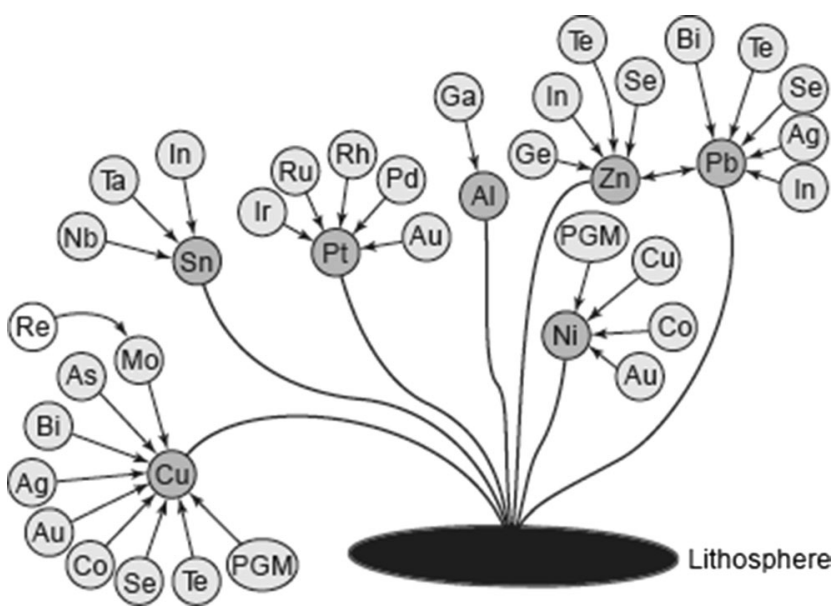

Fig. 2 Example of linkages of different metals to one another, demonstrating potential co-products in the production processes (Graedel and van der Voet 2010)

Tables 1, 2, and 3 provide these general best practices as agreed on by the participating metal associations. These tables show a high-level overview of allocation procedures, recommendations, and rationales for base metals, precious metals, and non-metal co-products. Situations will call for deviations from the preferred approaches; in these cases, the rationale for deviation should be discussed within the LCA report. Note, the focus of these tables is primary metal production; secondary production is not discussed in this paper.

Multiple different allocation approaches can be used in a single product system when distinct sets of processes and products (e.g., upstream versus downstream) can be identified. For metals, upstream processes (e.g., mining and concentration) are best characterized using mass allocation, while downstream processes (e.g., smelting and refining) are best characterized using economic allocation for the metal coproducts. The rationale is that generally the upstream processes needed to produce the concentrate are independent of the type of metal in the ore, while the downstream processes needed to extract the metal co-product from the concentrate are dependent on the metal in the ore. However, the contributions of each process may change, so where the value of different co-products varies widely, some care is required to ensure that the general rationale can be justifiably applied.

The copper industry employed this technique in a recent LCA study. The report argues that for mining, "ore

Table 1 Co-product approaches, recommendations, and rationales for base metals

\begin{tabular}{|c|c|c|}
\hline Co-product type & Approach & Recommendation/rationale \\
\hline \multirow{8}{*}{$\begin{array}{l}\text { Base metals (co-products include } \\
\text { only base metals that are found } \\
\text { within the same mine) } \\
\text { Examples: } \\
\text { - Copper } \\
\text { - Molybdenum } \\
\text { - Nickel } \\
\text { - Lead } \\
\text { - Zinc }\end{array}$} & \multirow[t]{2}{*}{ Mass allocation (metal) } & Preferred approach \\
\hline & & $\begin{array}{l}\text { Mass is a consistent physical property of the metal and allows for a geographic } \\
\text { and temporal consistency. Although mass does not capture the economic purpose } \\
\text { for extracting and refining multiple metals, differences in market value between } \\
\text { many base metals are generally relatively small. From a physical perspective, } \\
\text { the same effort is needed to extract a unit mass of ore, regardless of the metal } \\
\text { type or content. For base metal co-products with large market value differences, } \\
\text { economic allocation should be considered }\end{array}$ \\
\hline & \multirow[t]{2}{*}{ Mass allocation (total) } & Use as appropriate \\
\hline & & $\begin{array}{l}\text { Allocation by total mass may be appropriate when various metals in the ore are } \\
\text { combined or are otherwise difficult to separate using other allocation methods. } \\
\text { As with allocation by mass of metal, allocation by total mass captures the } \\
\text { physical effort needed to extract a unit mass of ore. Allocation by total mass does } \\
\text { not account for different quantities of the metal co-products in the ore; allocation } \\
\text { by mass of metal is generally preferred due to this limitation }\end{array}$ \\
\hline & \multirow[t]{2}{*}{ Economic allocation } & Use as appropriate \\
\hline & & $\begin{array}{l}\text { Economic allocation may be appropriate when there are relatively large differences } \\
\text { in the market value of the base metals. In these cases, allocation by mass of metal } \\
\text { does not adequately capture the economic purpose for extracting and refining the } \\
\text { base metals. If chosen, market data should be averaged over a long time span } \\
\text { (10-year average is recommended) so as to minimize the effect of price volatility } \\
\text { Note: it may be appropriate to allocate upstream processes (e.g., mining and } \\
\text { concentration) using mass of metal and downstream processes (e.g., smelting and } \\
\text { refining) using economic allocation }\end{array}$ \\
\hline & \multirow[t]{2}{*}{ System expansion ${ }^{\mathrm{a}}$} & Preferred approach (when data is available) \\
\hline & & $\begin{array}{l}\text { System expansion is preferred when LCI data for mono-output alternative routes } \\
\text { are available for the co-products. In case of metals, mono-output alternative } \\
\text { routes, or the LCI data associated with those routes, are often not available for } \\
\text { the co-products; allocation should be used in these instances }\end{array}$ \\
\hline
\end{tabular}

\footnotetext{
${ }^{a}$ It is acknowledged that this is not an allocation method but rather a method of avoiding its application according to ISO standards
} 
Table 2 Co-product approaches, recommendations, and rationales for precious and rare metals

\begin{tabular}{l} 
Co-product type \\
\hline Precious metals (co-products include \\
precious metals that are found with \\
other base or precious metals in the \\
same mine) \\
Examples \\
- Silver \\
- Gold \\
- Platinum group metals
\end{tabular}

Mass allocation (metal)

Mass allocation (total)

System expansion $^{\mathrm{a}}$
Recommendation/rationale

Preferred approach

Economic allocation accounts for the large disproportionately high market value of precious metals and the corresponding differences in price between metal co-products. Economic allocation captures the economic purpose for extracting and refining metals. If chosen, market data should be averaged over a long time span (10-year average is recommended) so as to minimize the effect of price volatility

Use as appropriate

Mass allocation does not account for the large differences in price between precious metals and base metals. However, in certain instances (e.g., where price is highly variable or uncertain), it may be necessary or useful to allocate co-products using the mass of metal content

Note: it may be appropriate to allocate upstream processes (e.g., mining and concentration) using mass of metal and downstream processes (e.g., smelting and refining) using economic allocation

Use as appropriate

Similar to allocation by mass of metal, allocation by total mass may be necessary when economic allocation is not possible. Allocation by total mass (i.e., total ore) may be appropriate when various metals in the ore are combined are otherwise difficult to separate using other allocation methods. As with allocation by mass of metal, allocation by total mass captures the physical effort needed to extract a unit mass of ore. Allocation by total mass does not account for different quantities of the metal co-products in the ore. Allocation by mass of metal is generally preferred due to this limitation

Preferred approach (when data is available)

System expansion is preferred when LCI data for mono-output alternative routes are available for the co-products. In case of metals, mono-output alternative routes, or the LCI data associated with those routes, are often not available for the co-products; allocation should be used in these instances

${ }^{\mathrm{a}}$ It is acknowledged that this is not an allocation method but rather a method of avoiding its application according to ISO standards

Table 3 Co-product approaches, recommendations, and rationales for non-metal co-products

\begin{tabular}{|c|c|c|}
\hline Co-product type & Approach & Recommendation/rationale \\
\hline \multirow{7}{*}{$\begin{array}{l}\text { Non-metals (metals with production } \\
\text { of non-metal products) }\end{array}$} & \multirow[t]{2}{*}{ System expansion } & Preferred approach \\
\hline & & $\begin{array}{l}\text { Alternative production routes are often available for non-metal co-products, } \\
\text { making this a preferred approach for dealing with co-products. System } \\
\text { expansion can be used for slags, process gases, and other non-metal } \\
\text { co-products }\end{array}$ \\
\hline & \multirow[t]{2}{*}{ Mass allocation (total) } & Use with caution \\
\hline & & $\begin{array}{l}\text { Allocation of non-metal co-products by total mass may be appropriate when } \\
\text { information (e.g., LCI data) for the co-product is unavailable. It is assumed } \\
\text { that allocation by total mass does not account for economic purpose for } \\
\text { generating co-products; thus, the market value should be similar between } \\
\text { co-products so as to avoid unfair impact allocation }\end{array}$ \\
\hline & \multirow[t]{2}{*}{ Economic allocation } & Use with caution \\
\hline & & $\begin{array}{l}\text { Allocation of non-metal co-products by market value may be appropriate when } \\
\text { information (e.g., LCI data) for the co-product is unavailable. Economic } \\
\text { allocation accounts for the economic purpose for generating co-products. If } \\
\text { chosen, market data should be averaged over a long time span (10-year } \\
\text { average is recommended) so as to minimize the effect of price volatility }\end{array}$ \\
\hline & Mass allocation (metal) & $\mathrm{n} / \mathrm{a}$ \\
\hline
\end{tabular}

$n / a$ not available 
(containing a mix of metals) is considered to be mining's only product, so no allocation is made. However, if two different ores are mined, a total mass allocation is used. There is no difference in process effort or yield for different grades of metal ores." For the refining processes, the report argues that "since the precious metal outputs have such disparate economic value and mass outputs compared to copper cathode, using the transparent market prices of the commodities copper, gold, silver and nickel sulfate to reflect the society value, is a substantial and appropriate approach for the treatment of the metal co-products $\rightarrow$ market value allocation." Similarly, use of different allocation approaches at various stages in the metal production process should be applied based on the recommendations in Tables 1, 2, and 3.

\subsubsection{Special allocation scenarios}

Tables 1, 2, and 3 provide insight into recommended allocation approaches for basic metal systems. However, production systems for certain metals and products are often complex, particularly when multiple metals are simultaneously produced or utilized without being separated. A common example of such a system is ferroalloys and their products.

Ferroalloys occur where ferrous and non-ferrous products are produced together as a single material. A common use of ferroalloys is ferronickel in the production of stainless steel. The iron in the ferroalloy substitutes the need for other iron inputs; the substitution should be accounted for appropriately in the LCI calculations.

The following bullets summarize the recommended treatment of ferroalloys in a metal system:

- Ferroalloys are often best viewed as single, aggregated materials and, ideally, their environmental impacts will not be broken down to the constituent elements;

- The elemental ratio (e.g., $x \% \mathrm{Fe}$ and $y \% \mathrm{Ni}$ ) should be reported when presenting environmental impact results; and

- If it is necessary to break down impacts into the constituent elements, the impacts need to be fairly distributed across both the ferrous and non-ferrous components. It is recommended that the impacts from the ferrous component are credited to the non-ferrous component using system expansion. Practitioners should be careful to apply the credit using an equivalent ferrous product, such as scrap, rather than sinter, pellet, hot metal, or finished steel products. System expansion is justified here because iron is predominately produced in isolation from other metals.

A similar set of rules can be developed applied for other multi-metal systems that exhibit similar allocation complexities as ferroalloys.

\subsection{Recycling allocation}

Recycling is a key consideration in the metal life cycle due to metals' high recycling potential. Unlike some other materials, metals can be recycled indefinitely, without any loss of their properties, if contamination with foreign materials and material losses are avoided. It is important to capture this feature of the metal life cycle when assessing the potential environmental impacts of producing the raw materials themselves or the products that they form.

In 2006, the metal industry published its Declaration by the Metals Industry on Recycling Principles, in which it endorses the end-of-life recycling approach:

For purposes of environmental modeling, decision-making, and policy discussions involving recycling of metals, the metals industry strongly supports the endof-life recycling approach over the recycled content approach.

...Of particular concern, pursuit of recycled content may generate market distortions and result in environmental and economic inefficiencies.

This declaration represents a consensus metal industry position, as it was endorsed by all the major global metal commodity associations, as well as national/regional metal associations (Atherton 2007). Notable research institutions such as Yale University's Stocks and Flows Project and the UNEP International Resource Panel's Working Group on Global Metal Flows also endorse taking an end-of-life recycling approach (Reck and Graedel 2012; UNEP 2011).

\subsubsection{Recycling in EN 15804}

EN 15804 requires that the recycled content input is characterized in module A1 (raw material supply). The recyclability of metals can still be accounted for through the use of module $\mathrm{D}$, where credits can be applied to the system based on avoided burden. In order to avoid double counting of recycling benefits from both recycled content and end-of-life recycling, the avoided burdens are calculated in module $\mathrm{D}$ based on the net flow of secondary materials (i.e., scrap in the case of metals) exiting the product system. This is calculated as the flow of collected end-of-life scrap minus the flow of scrap used at the production stage. This approach ensures that only the net recycling is accounted for, which is consistent with the avoided burden allocation approach.

The following are notes from EN 15804 that apply to recycling and end of life (CEN 2013).

- A1 input side: Recycling processes of materials used as input for the manufacture of the product, but not including 
those processes that are part of the waste processing in the previous product system.

- C3-4: The end-of-life stage of the construction product starts when it is replaced, dismantled, or deconstructed from the building and does not further provide any functionality to the building. The end-of-life system boundary of the construction product system is set where outputs, e.g., materials, products, or building elements, have gained an economic value or where the end-of-waste stage is reached, whichever occurs first. The end-of-waste status is reached when it complies with the following conditions:

- the material, product, or building element is commonly used for specific purposes

- a market or demand exists for such a material, product, or building element

- the material, product, or building element fulfills the technical requirements for the specific purposes and meets the existing legislation and standards applicable to products - the use of the material, product, or building element will not lead to overall adverse environmental or human health impacts

The goal of EN 15804 was to ensure that national schemes be based on a common European program founded upon European or international standards for EPDs. EPD schemes in Germany (IBU), Sweden (International EPD System), and the UK (BRE) have revised their scheme rules to align with EN 15804. National standards in the Netherlands and France have also been revised accordingly.

\subsubsection{Recommendations for recycling allocation}

The recyclability of metals is a key material property. The recycled content methodology does not account for quality of the material produced for recycling and is thus not the preferred approach to end-of-life allocation. Rather, the avoided burden methodology is the preferred allocation approach due to its inclusion of recycling rate, as well as the ability to account for downcycling and recycling efficiencies.

It is important to acknowledge that accurate recycling rates are sometimes difficult to ascertain. Accurate calculation of recycling rates requires considering not just consumption and capture but also imports and exports, time difference between consumption and capture, recycling yields, and other factors. Metal associations sometimes publish their calculated rates in their respective LCA reports and/or other communication documents. Rates can also be found in journal articles, such as Graedel et al. (2011). Regardless of the source, care should be taken to establish accurate recycling rates and sensitivity analyses should be used to capture uncertainty and/or variability in these rates.

\subsection{Life cycle impact assessment}

Life cycle impact assessment (LCIA) "aims at understanding and evaluating the magnitude and significance of the potential environmental impacts for a product system throughout the life cycle of the product" (ISO 14044 2006). Whereas the life cycle inventory considers emissions and other flows from or to the environment, LCIA accounts for the potential impacts of those flows on humans, ecosystems, and resources. Due to the relative approach of LCA, which is based on a functional unit rather than on total environmental loads, LCIA results are relative expressions and do not predict impacts on category endpoints, the exceeding of thresholds, safety margins, or risks.

The science that supports the characterization of impacts varies in quality from category to category. Some categories, such as global warming potential, are well-established and have a high level of consensus in the LCA community. Other categories, such as toxicity, biodiversity, or resource depletion, rely on more controversial assumptions and methods and are thus less widely used and accepted in LCAs. The following set of impact categories are recommended for use in LCAs involving metals:

- Global warming potential,

- Acidification potential,

- Eutrophication potential,

- Smog potential, and

- Ozone depletion potential.

The choice in these five impact categories is recommended based on several factors. First, the availability and quality of the LCI data that contributes to these categories tend to be high. Second, the impact assessment methods for these categories, while still evolving, are relatively mature compared to other impact categories. Third, these five impacts are commonly reported in most LCAs for metals and other materials and products; thus, there is precedent for continuing to report these categories.

In addition to these categories, certain life cycle inventory metrics should be reported. In particular, primary energy demand (total, fossil, and renewable), net water consumption, and waste generation should be part of the LCA reporting. Although these inventory metrics do not measure impact (as do LCIA categories), they are important parts of the environmental profile and have become commonly reported in most LCAs.

There are many other LCIA categories available to LCA practitioners. It is important to note that the selection of impact categories should meet the product and the goals of the study, as well as follow any relevant standards or guidelines, such as those found in product category rules when developing environmental product declarations. Thus, certain impact 
categories may need to be included, regardless of recommendations from the metal industry.

In general, impacts related to resource depletion, toxicity to humans and ecosystems, land use change, and water scarcity are not recommended to be reported for metal LCAs. Among these, all are labeled as level II or III within the ILCD handbook (JRC 2011), meaning that they are recommended by ILCD but "in need of some improvements" or "to be applied with caution." Although these impacts are relevant environmental concerns, it is the position of the metal industry that the characterization of these impacts from the inventory data does not adequately support decision-making. As the supporting science improves and the LCI data becomes more robust (e.g., higher spatial resolution), inclusion of these impact categories should be periodically reconsidered. For certain impact categories, there are also other sources of information which can be considered when assessing performance of materials as appropriate, such as metal risk assessments and Registration, Evaluation, Authorisation and Restriction of Chemicals (REACH) registration dossiers which are available for many metals. Although practitioners have a choice in which impact categories and inventory metrics to report in the documentation, the LCI datasets themselves should contain accurate and comprehensive inventory data, given reasonable accessibility and data collection cost constraints. This may include, as appropriate, data to support analysis beyond LCA as well as the calculation of impact categories which are not necessarily included in LCA reports or other public communication material. An extensive discussion of the recommendations related to LCIA was provided, by the participating associations in this harmonization effort, in a guidance document which preceded this article (PE International 2014).

\section{Discussion}

Market and regulatory demands for life cycle data from the metal and mineral industry are increasing, as is sector activity in this field, particularly with regard to the development of life cycle inventory data. The importance of having a consistent approach across the metal and mineral industry is also being driven by an increase in the life cycle-based efforts of governments and regulators, the end-use market sectors, civil society, multi-lateral organizations (e.g., United Nations International Resource Panel, European Commission), and material suppliers. While the specific efforts of these groups vary, their objectives rely on having accurate and consistent information on the environmental impacts of their materials and products.

The main intent of this alignment effort is to create a common voice for the metal industry on life cycle methodologies when engaging with various stakeholders. The guidance developed through the creation of this article is intended for use by associations and companies within the metal and mineral industry to support engagement and communication with various stakeholders, including the following:

- Regulators,

- Life cycle database providers,

- LCA practitioners, and

- Industry groups related to the metal and mineral sector.

Methodological alignment for LCA studies in the metal and mining industry will lead to improved consistency and applicability of the LCA data and results. The recommendations developed through this research improve the consistency of decisions regarding system boundary, recycling allocation, co-product allocation, and impact assessment categories. Further research is suggested to improve the specificity of certain recommendations (such as those with allocation), as well as expand the scope of the harmonization efforts to include other methodological decisions.

Acknowledgments This harmonization initiative was spearheaded and funded by the International Copper Association (ICA) and through inkind contributions from representatives of the following associations: Aluminum Association, Cobalt Development Institute, Eurometaux, Euromines, International Aluminium Institute, International Council on Mining and Metals, International Lead Association, International Manganese Institute, International Molybdenum Association, International Stainless Steel Forum, International Zinc Association, Nickel Institute, and World Steel Association. The participating organizations were supported by thinkstep (previously PE INTERNATIONAL) to develop this article.

Open Access This article is distributed under the terms of the Creative Commons Attribution 4.0 International License (http:// creativecommons.org/licenses/by/4.0/), which permits unrestricted use, distribution, and reproduction in any medium, provided you give appropriate credit to the original author(s) and the source, provide a link to the Creative Commons license, and indicate if changes were made.

\section{References}

Ardente F, Cellura M (2012) Economic allocation in life cycle assessment. J Ind Ecol 16(3):387-398

Atherton J (2007) Declaration of the metals industry on recycling principles. Int J Life Cycle Assess 12:59-60

CEN (2013) European Standard EN 15804:2012+A1:2013: sustainability of construction works - environmental product declarations - core rules for the product category of construction products

Cooper JS (2003) Specifying functional units and reference flows for comparable alternatives. Int J Life Cycle Assess 8(6):337-349

European Commission (2014) Environmental Footprint Pilot Guidance document - guidance for the implementation of the EU Product Environmental Footprint (PEF) during the Environmental Footprint (EF) pilot phase, v. 4.0, May 2014. http://ec.europa.eu/ environment/eussd/smgp/pdf/Guidance_products.pdf. Accessed 12 June 2015

Graedel TE, van der Voet E (2010) Linkages of sustainability. Strungmann Forum Report. MIT Press. https://mitpress.mit.edu/ sites/default/files/titles/content/9780262013581_sch_0001.pdf. Accessed 12 June 2015 
Graedel TE, Allwood J, Birat J-P, Buchert M, Hagelüken C, Reck B, Sibley S, Sonnemann G (2011) What do we know about metal recycling rates? J Ind Ecol 15:355-366

ISO 14040 (2006) International Standard ISO 14040: environmental management-life cycle assessment-principles and framework Geneva, Switzerland

ISO 14044 (2006) International Standard ISO 14044: environmental management-life cycle assessment-requirements and guidelines Geneva, Switzerland

JRC (2011) ILCD Handbook: recommendations for life cycle impact assessment in the European context. European Commission Joint Research Centre Institute for Environment and Sustainability. http://eplca.jrc.ec.europa.eu/?page id=86. Accessed 12 June 2015

Koffler C, Geyer R, Volz T (2014) Life cycle inventory. In: Schenk R, White P (eds.): Environmental life cycle assessment - measuring the environmental performance of products. American Center for Life Cycle Assessment, pp 46-58
PE International (2014) Harmonization of LCA methodologies for metals - a whitepaper providing guidance for conducting LCAs for metals and metal products. https://www.icmm.com/page/ 102613/harmonization-of-life-cycle-assessment-methodologies-formetals. Accessed 25 September 2015

Reck BK, Graedel TE (2012) Challenges in metal recycling. Science 337(6095):690-695

Tuusjarvi M, Vuori S, Maenpaa I (2012) Metal mining and environmental assessments: a new approach to allocation. J Ind Ecol 16(5):735747

UNEP (2011) Recycling rates of metals - a status report, a report of the Working Group on the Global Metal Flows to the International Resource Panel. Graedel TE, Allwood J, Birat J-P, Reck BK, Sibley SF, Sonnemann G, Buchert M, Hagelüken C (eds). http:// www.unep.org/resourcepanel/Portals/24102/PDFs/Metals Recycling_Rates_110412-1.pdf. Accessed 12 June 2015 